\title{
Elaboração de jogos de empresa para auxiliar na gestão operacional e ambiental de terminais de contêineres: O caso do jogo Tecon-Ambiental
}

\author{
Suellem Deodoro Silva', Pítias Teodoro², Luíza Santana França ${ }^{3}$ e Márcio de Almeida D’Agosto ${ }^{4}$
}

\begin{abstract}
Resumo: O objetivo deste trabalho é relatar o desenvolvimento de um jogo de empresas, com aplicação em cursos de gestão portuária, capaz de simular as principais operações de um terminal de contêineres e seus impactos ambientais. A revisão bibliográfica contempla a atividade portuária, seus impactos ambientais e a formação de gestores para atuarem na área de planejamento operacional de terminais de contêineres, por meio do emprego de jogos de empresas. O método utilizado foi o Estudo de Caso tendo o desenvolvimento do jogo de empresas TECON-AMBIENTAL como objeto de estudo. As técnicas utilizadas para coleta de dados foram revisão bibliográfica e análise documental. Os resultados mais relevantes indicam que o planejamento operacional de terminais de contêineres e os impactos ambientais desta atividade podem ser considerados de forma conjunta em um ambiente simulado - jogo de empresas - para formação de gestores que atuam na área portuária. Conclui-se, que as variáveis operacionais e ambientais utilizadas possuem verossimilhança com a realidade e que a simulação realizada por meio do uso do jogo de empresas TECON-AMBIENTAL possui elementos suficientes para que haja transferência de conhecimento, desenvolvimento de habilidades e incentivo a atitudes, proporcionando que o participante aplique o que aprendeu em outras situações.

Palavras-chave: Jogos de empresas; Aprendizagem; Transporte aquaviário; Terminal de contêiner.
\end{abstract}

\begin{abstract}
The aim of this paper is to report the development of a business game, with applications in port management courses, capable of simulating the main operations of a container terminal and its environmental impacts. The literature review includes the port activity, its environmental impacts and training managers to work in operational planning area of container terminals, through the use of business games. The method used was the case study with the development of the business game TECONENVIRONMENTAL as objects of study. The techniques used for data collection were literature review, and document analysis. The most relevant results indicate that the operational planning of container terminals and the environmental impacts of this activity can be considered jointly in a simulated environment - business game - to train managers working in the port area. It is concluded that the operational and environmental variables used have verisimilitude with reality and the simulation performed by using the business game TECON-ENVIRONMENTAL has enough elements so that there is transfer of knowledge, skills and encouraging attitudes, providing the participant to apply what you have learned in other situations.
\end{abstract}

Keywords: Business games; Learning; Water transportation; Container terminal.

\section{INTRODUÇÃO}

O transporte aquaviário tem apresentado crescimento contínuo no volume transportado nos últimos anos (Frigo e Bleninger, 2015; ANTAQ, 2013). Entre as decorrências desta tendência, destacam-se nesse trabalho o aumento na demanda por mão de obra especializada e o aumento dos impactos ambientais da atividade de transporte aquaviário. No Brasil, a qualificação para o setor tem sido realizada, por meio de cursos técnicos e de pós-graduação que visam suprir a carência de profissionais com formação específica nas áreas de transporte e logística para atuar no setor marítimo/ portuário (Silva et al 2013). Como a redução da influência que a atividade portuária causa ao meio ambiente deveria ser considerada em sua gestão, trata-se de um dos aspectos

\footnotetext{
${ }^{1}$ Suellem Deodoro Silva, Instituto Nacional de Pesquisas Hidroviárias INPH/SEP/IVIG/COPPE (suellem_04@hotmail.com)

${ }_{2}^{2}$ Pítias Teodoro, Universidade Federal Fluminense e Universidade Federal do Rio de Janeiro (pitiasteodoro@yahoo.com.br)

${ }^{3}$ Luíza Santana França, Universidade Federal do Rio de Janeiro

(luizasfranca@poli.ufrj.br)

${ }^{4}$ Márcio de Almeida D’Agosto, Universidade Federal do Rio de Janeiro (dagosto@pet.coppe.ufrj.br)
}

Manuscrito recebido em 19/12/2013 e aprovado para publicação em 21/12/2015.

Este artigo é parte de TRANSPORTES v. 24, n. 1, 2016 ISSN: 2237-1346 (online). DOI:10.14295/transportes.v24i1.755 que devem estar presentes nos programas de capacitação profissional para o setor.

Por meio de pesquisa bibliográfica foi constatado que, no Brasil, só existe um jogo para apoiar o processo de aprendizagem de planejamento operacional de terminais de contêineres, o jogo do TECON (Jogo de Terminais de Contêineres), elaborado por Silva (2010), entretanto, este jogo não considera questões ambientais portuárias. Assim, a associação da demanda por qualificação no setor aquaviário às questões ambientais desta atividade, acabou gerando uma oportunidade: desenvolver um jogo de empresas para o setor portuário que considerasse tanto a operação quanto os impactos ambientais da própria operação.

Somam-se à proposta de formação de gestores com ênfase no planejamento operacional de terminais de contêineres e seus impactos ambientais, os benefícios do uso do jogo de empresas como ferramenta de apoio ao processo de aprendizagem (Silva et al., 2013). De acordo com Luperini (2008), os jogos funcionam como um laboratório, no qual é possível testar estratégias, decisões e avaliar resultados, podendo ser usados em programas de capacitação, difusão do conhecimento ou para reflexão sobre determinado tema.

Motta, Melo e Paixão (2012) apontam que as principais vantagens do uso dos jogos de empresas no processo de ensino-aprendizagem são: 1) Auxílio no treinamento para o processo decisório; 2) Vivência simulada das atividades 

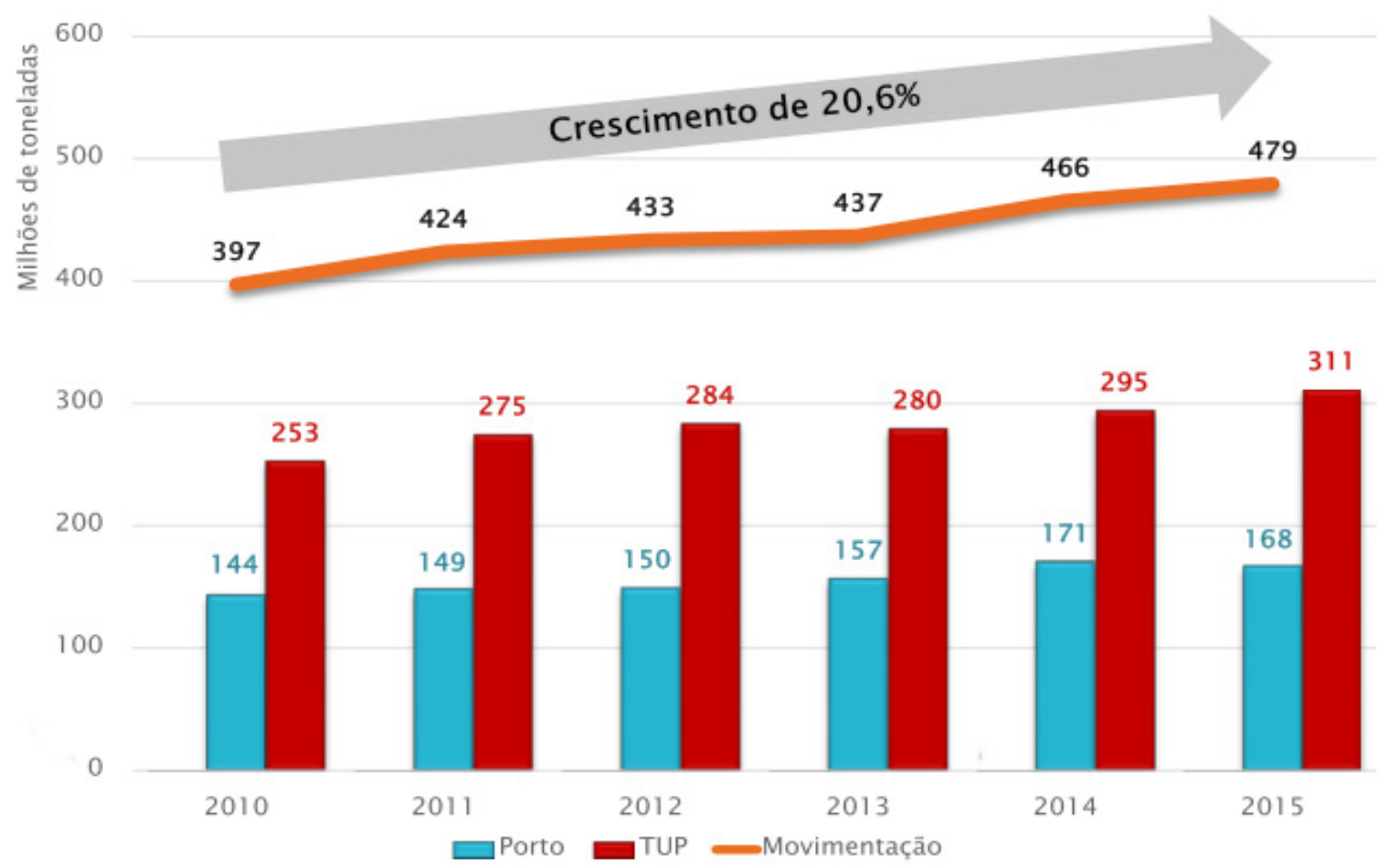

Figura 1: Histórico do movimento de cargas em portos e terminais de uso privado (TUP) no Brasil. Fonte: ANTAQ (2015a)

empresariais; 3) Desenvolvimento de habilidades interpessoais para o trabalho em equipe e 4) Aplicação dos conhecimentos adquiridos ao longo do curso. Isto é possível porque um jogo de empresas representa a realidade de um ambiente de negócios, destacando o que é relevante. A fração da realidade representada tem o propósito de convencimento dos participantes de que os efeitos verificados na simulação são os mesmos presentes na vida real.

Nesse contexto, foi desenvolvida uma nova versão do Jogo do TECON, o Jogo TECON-AMBIENTAL, capaz de simular, além do planejamento operacional de terminais de contêineres, alguns dos principais impactos ambientais desta atividade, contribuindo para uma melhor capacitação dos profissionais da área de gestão operacional e ambiental de terminais de contêineres.

Desta forma o objetivo deste artigo é relatar o desenvolvimento de um jogo de empresas, com aplicação em cursos de gestão portuária, capaz de simular as principais operações de um terminal de contêineres e seus principais impactos ambientais.

O presente artigo é um Estudo de Caso (Yin, 2001), de natureza aplicada e possui objetivo descritivo. Quanto aos meios empregados, foi realizada revisão bibliográfica e análise documental (Gil, 2005; Silva e Menezes, 2001). O objeto de estudo é o desenvolvimento do jogo de empresas TECON-AMBIENTAL. Quanto à estrutura, o artigo possui três seções, além dessa introdução e da seção com as referências bibliográficas. Na seção 2 há a revisão bibliográfica sobre a atividade portuária, com destaque aos terminais de contêineres, e sua influência ambiental. Na seção 3 há a apresentação das etapas para elaboração de um jogo de empresas, os elementos considerados nestas etapas para o desenvolvimento do jogo de empresas TECON-AMBIENTAL e a descrição de seu uso. Na seção 4 são apresentadas as considerações finais com a síntese dos resultados, limitações e sugestão de estudos complementares.

\section{SETOR PORTUÁRIO NO BRASIL}

O setor portuário brasileiro é responsável por movimentar 96\% do volume do comércio internacional do País. A expectativa é que o volume transportado continue crescendo nos próximos anos impulsionado principalmente pelas commodities e pelo incremento das relações comerciais brasileiras (ILOS, 2014). Na Figura 1 é apresentada a evolução da movimentação de cargas em portos brasileiros dos últimos 5 anos.

\subsection{Portos e terminais de contêineres}

Um porto ou terminal portuário é um complexo operacional, cujo objetivo é movimentar as cargas demandadas pelo tráfego de embarcações e pelo mercado de sua região de influência, no sentido navio-terra e vice e versa, buscando alcançar os níveis de operação e tarifação satisfatórios e que tragam competitividade (Valois, 2009).

De acordo com Coelho (2010), 36\% da movimentação de carga dos portos ao redor do mundo é de produtos a granel líquido, $24 \%$ de granéis secos e os $40 \%$ restantes de cargas variadas, que podem ser condicionadas em contêineres. Esta fração da carga internacional - granéis secos - que nos últimos 20 anos (a partir da década de 1990), tem contribuído para um aumento na movimentação de cargas contêinerizadas. 
O uso de contêineres reduziu o tempo de carregamento/descarregamento nos portos, otimizou espaços de armazenamento e possibilitou a utilização intermodal no transporte de cargas, tornando o processo mais rápido, seguro e eficaz (Gullo, 2007)

Para tanto, toda a infraestrutura do terminal de contêineres é planejada de modo a oferecer uma área para movimentação e armazenagem, além de equipamentos específicos para a sua operação. Os terminais necessitam basicamente de quatro áreas específicas para a sua operação: 1) Berço de atracação, 2) Faixa do cais, 3) Área de armazenagem e as chamadas. 4) Áreas de apoio (Goes Filho, 2008; Peixoto e Botter, 2005; Fernandes, 2001).

$\mathrm{O}$ volume de cargas conteinerizadas no Brasil tem acompanhado a tendência de aumento no volume anual transportado. Este tipo de carga teve uma movimentação de 75, 84, 87 e 98 milhões de toneladas nos portos brasileiros nos anos de 2010, 2011, 2012 e 2013, respectivamente (ANTAQ, 2013) chegando a 49,2 milhões de toneladas apenas no primeiro semestre de 2015 (ANTAQ, 2015a). O aumento do volume do comércio de cargas contêinerizadas gera uma cadeia de suprimentos cada vez mais usuária e dependente do desempenho e da produtividade dos terminais de contêineres (Peixoto e Botter, 2005).

A gestão portuária é formada por um conjunto de programas e práticas administrativas voltadas à coordenação de atividades realizadas na região do porto e seu entorno. Para que seja adequada, na gestão devem ser considerados vários aspectos que trarão confiabilidade nos serviços e competitividade (Goes Filho, 2008), entre os quais, os mais relevantes são: econômicos, financeiros, sociais, operacionais, ambientais e de gestão propriamente dito.

O desempenho operacional dos terminais de contêineres é diretamente influenciado pelos tipos e pela quantidade dos equipamentos portuários utilizados em cada uma de suas áreas, cuja operação envolve um conjunto muito grande de processos com interações entre sistemas e subsistemas portuários, e vários tipos de cargas (Carvalho, 2003).

O planejamento adequado das operações dos terminais de contêineres (do cais até os acessos terrestres) busca evitar restrições operacionais que possam influenciar nos índices de desempenho e produtividade desses terminais.

Por outro lado, Leal Jr et al. (2015), destacam a importância do equilíbrio entre a infraestrutura disponível e a efetivamente utilizada. Pesquisa realizada pelos autores demonstrou que terminais de contêineres brasileiros com níveis mais elevados de eficiência técnica (aqui tratada como operacional) não foram aqueles que apresentaram os maiores níveis de eficiência financeira em função das configurações de seus equipamentos e ou tamanho da operação e ou capacidade ociosa.

\subsection{A atividade portuária e sua influência ambiental}

Os gestores dos terminais portuários, de maneira geral, apoiam suas decisões e definem suas ações a partir de indicadores relacionados à eficiência operacional, tais como: quantidade de contêineres movimentados, preço médio, tempo de espera para atracação e prancha média, acrescidos de questões relacionadas como facilidades de acesso terrestre e marítimo, e infraestrutura operacional (Silva, 2010a). Entretanto, para que possam permanecer competitivos em um mercado no qual os aspectos ambientais crescem em importância relativa frente aos aspectos econômico-financeiros, os gestores dos terminais portuários precisam considerar processos de tomada de decisão adequados a esse contexto (Cruz, 1997).

A legislação brasileira qualifica a atividade portuária como potencialmente poluidora devido aos impactos que causa ao meio ambiente. A Lei $\mathrm{n}^{\circ} 6.938$, de 31 de agosto de 1981, que dispõe sobre a Política Nacional do Meio Ambiente, seus fins e mecanismos de formulação e aplicação, e dá outras providências, por meio de seu Anexo XIII, incluído pela Lei $\mathrm{n}^{\circ} 10.165$, de 27 de dezembro de 2000, classifica a atividade portuária como uma das atividades potencialmente poluidoras e utilizadoras de recursos ambientais: Código 18; Categoria: Transporte, terminais, depósitos e comércio e Descrição: Transporte de cargas perigosas, transporte por dutos; marinas, portos e aeroportos; terminais de minério, petróleo e derivados e produtos químicos; depósitos de produtos químicos e produtos perigosos; comércio de combustíveis, derivados de petróleo e produtos químicos e produtos perigosos (Brasil, 1981).

Em função da influência exercida por esta atividade no meio ambiente e a necessidade de balancear os objetivos de planejamento portuário com o gerenciamento ambiental, agravado pela crescente participação do modo aquaviário no comércio exterior, a ANTAQ determinou que todos portos brasileiros tenham um Sistema Integrado de Gestão Ambiental (SIGA) (ANTAQ, 2011).

O SIGA, com o objetivo de minimizar os impactos ambientais causados pela atividade portuária, deve ser concebido de maneira a tratar de forma organizada os assuntos ligados às áreas de Qualidade (Série ISO 9000), Proteção ao Meio Ambiente (Série ISO 14000) e Saúde e Segurança Ocupacional (BS 8800) (ANTAQ, 2011).

Entretanto, Carvalho e Abdallah (2012, p. 390) defendem que "o conceito moderno de gestão ambiental não é um sinônimo de fiscalização ou reação, mas uma postura pró-ativa, uma atitude que busca criar condições para harmonizar o desenvolvimento humano com a necessidade de assegurar a perenidade dos recursos naturais". Ao tratar da atividade portuária, seriam necessárias ações pró-ativas para equilibrar o desenvolvimento com a perenidade dos recursos naturais para impedir, reduzir e ou mitigar impactos ambientais que, segundo a ANTAQ (2011), podem ser classificados em três grupos: 1) Localização do empreendimento portuário, 2) Construção do empreendimento e 3) Operação portuária.

Pode-se destacar como principais impactos relacionados à localização do empreendimento: aumento do fluxo de trânsito de caminhões para a região, geração de emprego. Já os principais impactos relacionados à construção do empreendimento são a alteração de linha de costa, a supressão de vegetação e a modificação no regime de corpo d'água. Com relação aos impactos relacionados a operação portuária tem-se: emissão de poluentes e a geração de resíduos sólidos e líquidos (ANTAQ, 2015b).

\section{JOGO DE EMPRESAS}

O jogo de empresas é um tipo específico de simulação que, segundo Oliveira e Sauaia (2011), junto com o Método 


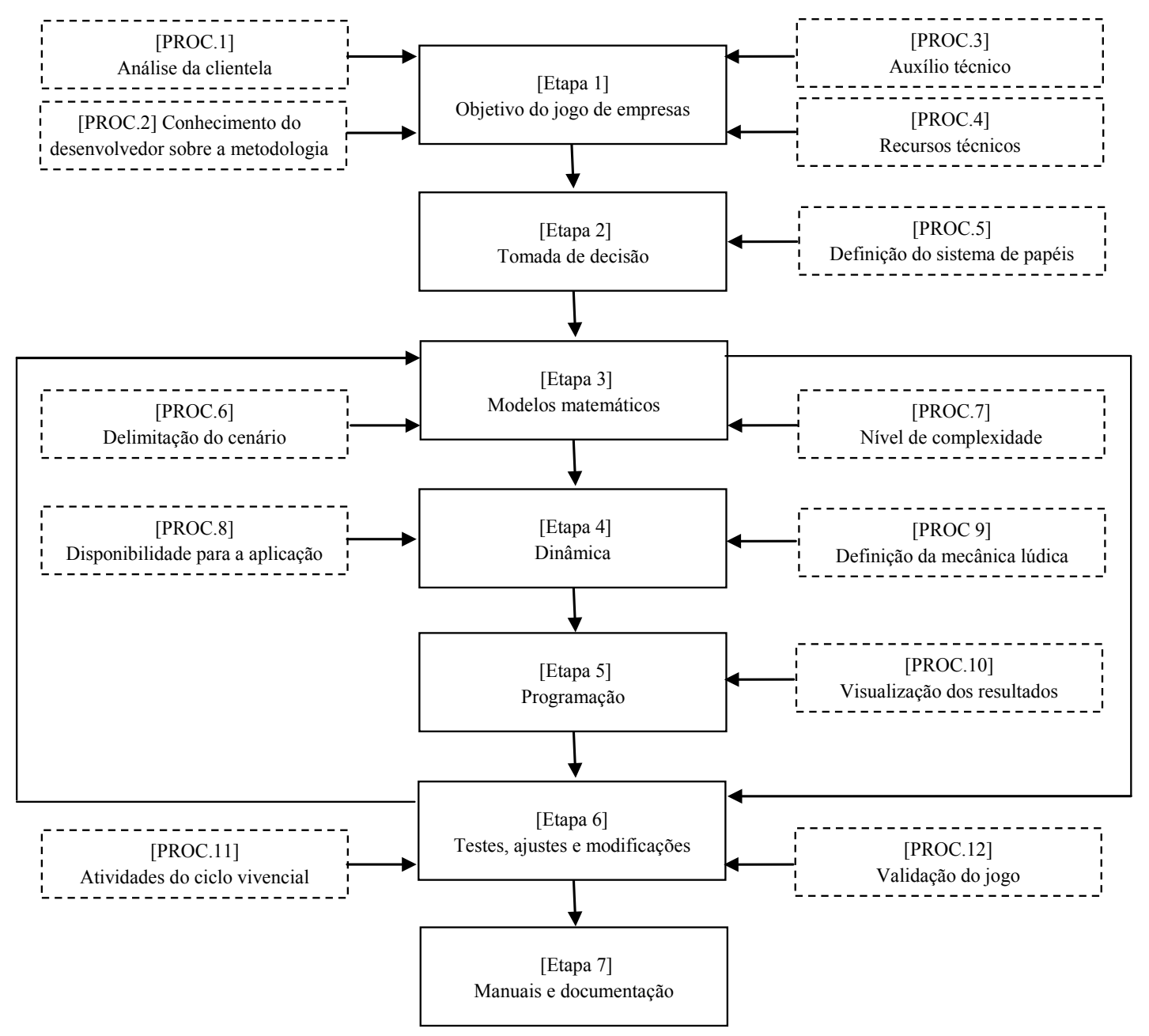

Figura 2: Etapas e procedimentos para a elaboração de jogo de empresas Fonte: adaptação de Silva (2010).

do caso e da aprendizagem baseada em problemas (PBL), são os principais métodos de aprendizagem vivencial utilizados. Trata-se de uma técnica de apoio ao processo de aprendizagem que cria um ambiente que representa, de forma simplificada, a estrutura e as relações presentes no ambiente organizacional (Teodoro, 2015). Já para Silva et al., (2013) o jogo de empresas é uma metodologia de ensino participativa que propicia a efetividade do ciclo de aprendizagem vivencial, possibilitando que o participante aplique seus conhecimentos teóricos em um ambiente que simula a realidade.

Os jogos de empresas podem ser classificados em sistêmicos e funcionais. No primeiro grupo todas as áreas organizacionais são contempladas na simulação, no segundo, uma determinada área é a referência para as situações problema (Keys e Biggs, 1990). O presente trabalho é direcionado ao segundo caso.

\subsection{Etapas para elaboração de um jogo de empresas}

O ambiente simulado por um jogo de empresas possui um contexto, que exige que os participantes tomem decisões relacionadas aos vários ciclos de gestão simulada (semanas, meses, anos), em um curto espaço de tempo (horas, dias, semanas), sem os ônus (operacionais e ou financeiros) que as possíveis decisões equivocadas provocariam no caso concreto (Teodoro et al., 2014).
Para Gramigna (2007), os jogos de empresas devem apresentar quatro características básicas: 1) Realidade da empresa simulada, capaz de reproduzir situações semelhantes às vivenciadas na empresa real; 2) Desenvolvido em um sistema de papéis, assumidos pelos participantes durante $\mathrm{o}$ jogo; 3 ) Conter regras claras e acessíveis, permitindo que o participante esteja ciente do que é proibido e permitido; 4) Condições (cenários) que façam com que o jogo seja atrativo e envolvente.

Quanto à reprodução da realidade, uma das características básicas de um jogo de empresa, as relações entre os agentes representados são sempre mais simples que a do mundo real (Tanabe, 1977). Em relação aos papéis que podem ser assumidos durante a realização do jogo, Gramigna (2007) esclarece que podem ser classificados em três categorias: estruturados, semi-estruturados e desestruturados. No jogo com papéis estruturados há o detalhamento para o participante das principais responsabilidades e comportamentos a serem adotados; no papel semi-estruturado as responsabilidades e comportamentos são definidos de forma genérica (o participante define qual adotar), enquanto no papel desestruturado, o participante define suas responsabilidades e comportamentos. As regras são parte do manual de instruções, por meio do qual são transmitidos para os participantes todas as informações necessárias para que seja possível explorar toda a potencialidade do jogo. Dentre as informações, destacam-se: 1) Objetivo(s) do jogo; 2) Regras de funcionamento: 3) Tempo de duração 
do jogo (quantidade de rodadas e duração de cada rodada) e 4) Formas de relacionamento entre os dados gerados pelo instrutor e pelos participantes. Quanto às condições para que seja atrativo e envolvente, além de uma interface amigável as relações devem ser tão diretas quanto possível. O jogo deve ser relativamente fácil de ser processado para que permita que os participantes sejam capazes de identificar as relações de causa e efeito de suas tomadas de decisão.

Para a elaboração de um jogo de empresas é necessário que sejam estabelecidos etapas e procedimentos. As sete etapas e os doze procedimentos definidos, respectivamente por D'Elboux (2008) e Gramigna (2007), foram consolidados por meio da Figura 2 de Silva (2010) que resume a proposta desse trabalho para a elaboração do jogo de empresas TECON-AMBIENTAL.

O conjunto de etapas pode ser tratado como um resumo das ações necessárias para elaboração de um jogo de empresas. O conjunto de procedimentos, como um resumo das ações para que as etapas possam ser cumpridas. Embora nesse trabalho não seja apresentado, esse conjunto de etapas e procedimentos terá, ainda, que ser desdobrado em outras atividades e com maior detalhamento, para que seja possível chegar ao nível de execução das atividades de desenvolvimento de um jogo de empresas.

A Etapa 1 - Determinar o objetivo do jogo de empresas - está vinculada a quatro procedimentos: analisar a clientela, determinar o conhecimento do desenvolvedor sobre jogos de empresas para verificar o tipo de auxílio técnico e determinar os recursos técnicos necessários. A Etapa 2 - Tomada de decisão é vinculada ao papel que cada participante irá assumir durante o jogo. A Etapa 3 - Modelos matemáticos - depende da delimitação dos cenários e do nível de complexidade desejado. A Etapa 4 - Dinâmica - é dependente de como será desenvolvido o simulador visto que este determinará a forma de interação entre os participantes. Além disso, a dinâmica depende do tempo e espaço disponíveis para a aplicação A Etapa 5 - Programação - forma como os participantes irão fazer os registros das decisões e como terão acesso aos seus resultados ao longo dos ciclos operacionais simulados no jogo. A Etapa 6 - Testes, ajustes e modificações - validação do jogo até que ele atenda os objetivos para o qual foi desenvolvido. A Etapa 7 - Manuais e documentação - formaliza o objetivo do jogo de empresas, informa quais ações os gestores das empresas simuladas deverão tomar para que o objetivo do jogo seja atingido, define como será avaliado os resultados (parcial e final) e esclarece as normas e as relações entre os agentes do ambiente simulado.

\subsection{Elaboração do jogo de empresas TECON- AMBIENTAL}

O jogo foi elaborado a partir das etapas e procedimentos apresentados na Figura 2. As áreas de terminais e os respectivos layouts utilizados no jogo TECON-AMBIENTAL foram os mesmos desenvolvidos por Silva (2010), inicialmente, para o jogo do TECON.

O jogo TECON-AMBIENTAL tem como foco o planejamento operacional de um terminal de contêineres, envolvendo o desempenho operacional e a capacidade de oferecer melhores tarifas. A atividade é realizada ao deslocar a demanda simulada de contêineres por meio de variáveis como investimentos (equipamentos, área e layout do terminal), perfil de operação (percentual de importação/exportação, tipos de contêineres movimentados, tipos de equipamentos) e impacto ambiental de equipamentos utilizados nestas operações (emissão de poluentes locais e globais do uso de: caminhão, reachstacker, transteiner e aranha).

O objetivo do jogo (etapa 1) é simular as operações portuárias de um terminal de contêineres, com ênfase nos processos de importação, exportação e armazenagem de contêineres, considerando as questões ambientais, tendo como público a ser atendido os alunos dos cursos técnicos na área de gestão portuária

A tomada de decisão (etapa 2) deve ser realizada a partir do conteúdo programático de cursos técnicos na área de gestão portuária. O Jogo do TECON possui 5 macroprocessos de tomada de decisão: 1) Determinar área de armazenagem; 2) Arrendar um layout de terminal de contêiner; 3) Investir em equipamentos portuários, 4) Analisar a capacidade de atendimento e 5) Determinar preço de movimentação de contêiner.

O modelo matemático (etapa 3) do jogo do TECON foi alterado recebendo as variáveis ambientais. Para incorporação das questões ambientais no jogo TECON-AMBIENTAL, foram considerados os impactos ambientais relativos à emissão de poluentes atmosféricos locais e globais $\left(\mathrm{CO}, \mathrm{HC}, \mathrm{NOx}, \mathrm{MP}\right.$ e $\left.\mathrm{CO}_{2}\right)$ provenientes da combustão interna dos equipamentos. Os equipamentos considerados foram o caminhão, reachstacker, transteiner e aranha.

O cálculo dos impactos ambientais envolveu os fatores de emissão relacionados a cada poluente, a velocidade média de cada equipamento e o consumo de óleo diesel por cada equipamento. Os fatores de emissão dos poluentes são baseados no Inventário de Emissões Veiculares do Rio de Janeiro (COPPE, 2011). Para a emissão de CO, HC, NOx e $\mathrm{MP}$, os fatores são relativos ao caminhão pesado na fase do PROCONVE P7. O fator de emissão do $\mathrm{CO}_{2}$ está relacionado ao óleo diesel. A velocidade média considerada de cada equipamento foi de $5 \mathrm{~km} / \mathrm{h}$ para o caminhão, $3 \mathrm{~km} / \mathrm{h}$ para o Reachstacker, $2,5 \mathrm{~km} / \mathrm{h}$ para o Transteiner e $0,75 \mathrm{~km} / \mathrm{h}$ para Aranha. O consumo de óleo diesel considerado foi que, para cada 11 consumido pelo motor, o caminhão roda 2,8 $\mathrm{km}$, o Reachstacker, 1,5 km, o Transteiner, $1 \mathrm{~km}$ e o Aranha, $0,5 \mathrm{~km}$. Considerando esses fatores, as Equações 1 e 2 apresentam os cálculos das emissões de poluentes atmosféricos.

$$
\begin{aligned}
& E_{\mathrm{CO}, \mathrm{HC}, \mathrm{NO}_{\mathrm{X}}, \mathrm{MP}=F E * V} \\
& E_{\mathrm{CO}_{2}}=F E * V * C
\end{aligned}
$$

$E_{\mathrm{CO}}, \mathrm{HC}, \mathrm{NO}_{\mathrm{X}}, \mathrm{MP}(\mathrm{g} / \mathrm{h})$ : Emissão de $\mathrm{CO}, \mathrm{HC}, \mathrm{NO}_{\mathrm{X}}$ e MP $F E_{\mathrm{CO}}, \mathrm{HC}, \mathrm{NO}_{\mathrm{X}}, \mathrm{MP}(\mathrm{g} / \mathrm{km})$ : Fatores de emissão de $\mathrm{CO}, \mathrm{HC}, \mathrm{NO}_{\mathrm{X}}, \mathrm{MP}$

$V(\mathrm{~km} / \mathrm{h})$ : Velocidade média de cada equipamento

$E_{\mathrm{CO}_{2}}(\mathrm{~kg} / \mathrm{h}):$ Emissão de $\mathrm{CO}_{2}$

(kg/l): Fatores de emissão de $\mathrm{CO}_{2}$

$C(1 / \mathrm{km})$ : Consumo de óleo diesel

A dinâmica (etapa 4) do jogo de empresas seguiu os mesmos processos definidos no jogo do TECON. O jogo foi desenvolvido para 4 equipes de até 4 jogadores cada, que interagem entre si por meio de um planilha em Excel programada com o uso do VBA(Visual Basic for Applications) no Excel ${ }^{\circledR}$. 
Tabela 1: Processos modelados matematicamente para o módulo das equipes

\begin{tabular}{|c|c|c|}
\hline & Processo & Indicador \\
\hline 1 & $\begin{array}{l}\text { Simulação do histórico de demanda para a região } \\
\text { da zona portuária do fundão (Contêineres e navios) }\end{array}$ & $\begin{array}{l}\text { Quantidade de contêineres por tipo (contêineres) } \\
\text { Quantidade de navios por tipo (navios) }\end{array}$ \\
\hline 2 & $\begin{array}{l}\text { Simulação da área de armazenagem necessária } \\
\text { para atender a demanda pretendida }\left(\mathrm{m}^{2}\right)\end{array}$ & Área de armazenagem $\left(\mathrm{m}^{2}\right)$ \\
\hline 3 & $\begin{array}{l}\text { Simulação do saldo da equipe/participante } \\
\text { após arrendar o layout de terminal e adquirir as } \\
\text { configurações para os berços (R\$) }\end{array}$ & Saldo financeiro (R\$) \\
\hline 4 & $\begin{array}{l}\text { Definição das pré-configurações para os berços } \\
\text { (tipos, quantidades e características operacionais, } \\
\text { financeiras e ambientais dos equipamentos) }\end{array}$ & $\begin{array}{l}\text { Produtividade (contêineres/h) } \\
\text { Valor do investimento }(\mathrm{R} \$)\end{array}$ \\
\hline 5 & Cálculo da consignação média por navio & Consignação média (contêineres/navios) \\
\hline 6 & Cálculo da produtividade do terminal & Produtividade (contêineres/h) \\
\hline \multirow{6}{*}{7} & \multirow{6}{*}{$\begin{array}{l}\text { Determinação da capacidade de atendimento do } \\
\text { terminal }\end{array}$} & Taxa média de chegada de navios (navios/dia) \\
\hline & & Tempo médio de atendimento (horas/navio) \\
\hline & & Taxa de ocupação do terminal (\%) \\
\hline & & Quantidade de navios atendidos (navios) \\
\hline & & Quantidade de navios não atendidos (navios) \\
\hline & & Contêineres movimentados (contêineres) \\
\hline \multirow{6}{*}{8} & \multirow{6}{*}{ Simulação dos custos do terminal } & Taxa de arrendamento por uso da área $\left(\mathrm{R} \$ / \mathrm{m}^{2}\right)$ \\
\hline & & $\begin{array}{l}\text { Taxa de arrendamento por contêineres movimentados }(\mathrm{R} \$ / \\
\text { contêiner) }\end{array}$ \\
\hline & & Manutenção (R\$/mês) \\
\hline & & Operação (R\$/mês) \\
\hline & & Mão-de-obra (R\$/mês) \\
\hline & & Custo total por contêiner (R\$/contêiner) \\
\hline \multirow{5}{*}{9} & \multirow{5}{*}{ Emissão de poluentes } & $\mathrm{CO}(\mathrm{g} / \mathrm{h})$ \\
\hline & & $\mathrm{HC}(\mathrm{g} / \mathrm{h})$ \\
\hline & & NOx $(g / h$ \\
\hline & & $\mathrm{MP}(\mathrm{g} / \mathrm{h})$ \\
\hline & & $\mathrm{CO} 2(\mathrm{~g} / \mathrm{h})$ \\
\hline \multirow{2}{*}{10} & \multirow{2}{*}{ Prego de movimentação do contêiner } & Prego de movimentação do contêiner cheio (R\$) \\
\hline & & Prego de movimentação do contêiner vazio (R\$) \\
\hline \multirow{3}{*}{11} & \multirow{3}{*}{ Indicador financeiro } & Receita total da movimentação (R\$) \\
\hline & & Custo total da movimentação $(\mathrm{R} \$)$ \\
\hline & & Lucro (R\$) \\
\hline \multirow{3}{*}{12} & \multirow{3}{*}{ Indicador operacional } & Tempo de operação (horas) \\
\hline & & Tempo médio de operação (horas/navio) \\
\hline & & Prancha média (contêineres/hora) \\
\hline \multirow{5}{*}{13} & \multirow{5}{*}{ Indicador ambiental } & Co (g/container) \\
\hline & & $\mathrm{HC}$ (g/contêiner \\
\hline & & NOx (g/contêiner) \\
\hline & & MP (g/contêiner) \\
\hline & & CO2 (kg/contêiner) \\
\hline \multirow{3}{*}{14} & \multirow{3}{*}{ Indicador de atratividade do terminal } & Indicador operacional \\
\hline & & Indicador financeiro \\
\hline & & Indicador ambiental \\
\hline
\end{tabular}


Tabela 2: Processos modelados matematicamente para o módulo do instrutor

\begin{tabular}{|c|c|c|}
\hline & Processo & Indicador \\
\hline \multirow{2}{*}{1} & \multirow{2}{*}{ Gerar a demanda da rodada (navios e contêiner) } & $\begin{array}{l}\text { Quantidade de gerações de navios (navios) } \\
\text { Demanda de navios (navios) }\end{array}$ \\
\hline & & $\begin{array}{l}\text { Tipos de contêineres (contêineres) } \\
\text { Demanda de contêineres (contêineres) }\end{array}$ \\
\hline 2 & $\begin{array}{l}\text { Calcular o indicador de atratividade de cada } \\
\text { terminal }\end{array}$ & $\begin{array}{l}\text { Produtividade (contêineres/h) } \\
\text { Custo da operação (R\$/Contêiner) }\end{array}$ \\
\hline 3 & $\begin{array}{l}\text { Distribuir a demanda da rodada em função do } \\
\text { indicador de atratividade }\end{array}$ & Demanda a ser movimentada (contêineres) \\
\hline 4 & $\begin{array}{l}\text { Calcular a área de armazenagem necessária para } \\
\text { cada terminal }\end{array}$ & Área de armazenagem $\left(\mathrm{m}^{2}\right)$ \\
\hline 5 & $\begin{array}{l}\text { Definir se os terminais possuem capacidade para } \\
\text { atender a demanda ganha }\end{array}$ & Capacidade instalada $\left(\mathrm{m}^{2}\right)$ \\
\hline 6 & Calcular os custos do terminal & $\begin{array}{l}\text { Manutenção (R\$/mês) } \\
\text { Operação (R } \$ / \text { mês) } \\
\text { Mão-de-obra (R } \$ / \text { mês) } \\
\text { Custo total (R } \$ / \text { mês) } \\
\text { Custo total por contêiner (R } \$ / \text { contêiner) }\end{array}$ \\
\hline 7 & Calcular a receita total do terminal & Receita total da movimentação (R\$) \\
\hline 8 & Calcular o lucro do terminal & Lucro $(\mathrm{R} \$)$ \\
\hline 9 & Calcular saldo financeiro do terminal & Saldo do terminal $(\mathrm{R} \$)$ \\
\hline 10 & $\begin{array}{l}\text { Calcular emissão de poluentes por tipo de } \\
\text { equipamentos }\end{array}$ & $\begin{array}{l}\mathrm{CO}(\mathrm{g} / \mathrm{h}) \\
\mathrm{HC}(\mathrm{g} / \mathrm{h}) \\
\operatorname{NOx}(\mathrm{g} / \mathrm{h}) \\
\mathrm{MP}(\mathrm{g} / \mathrm{h}) \\
\mathrm{CO} 2(\mathrm{~g} / \mathrm{h})\end{array}$ \\
\hline
\end{tabular}

Fonte: Elaboração própria (2014)

A programação (etapa 5) foi realizada a partir do jogo do TECON, que possuía dois módulos: O módulo das equipes, onde os participantes tomavam as suas decisões, sem a influência das equipes concorrentes e geravam uma proposta de gestão operacional, e o módulo do instrutor, onde as propostas de gestão operacional de todos os participantes eram comparadas e a partir dessa comparação tem-se o resultado do ciclo operacional indicando a equipe vencedora.

Nas Tabelas 1 e 2 são apresentados, respectivamente, os processos que foram modelados matematicamente e posteriormente programados para os módulos da equipe e do instrutor do jogo TECON-AMBIENTAL.

Para realização dos testes, ajustes e modificações (etapa 6), o jogo TECON-AMBIENTAL foi aplicado junto a um grupo de alunos selecionados do Programa de PósGraduação em Engenharia de Transportes (PET/COPPE/ UFRJ). O intuito do teste foi verificar a adequação da dinâmica de aplicação e os valores dos indicadores. Durante o primeiro teste percebeu-se um erro de programação no valor da emissão de poluentes. Após uma semana, o mesmo foi ajustado e realizou-se o teste final que permitiu a elaboração do manual de instruções.

O manual de instruções (etapa 7) utilizado para informar como é o uso do simulador, as interações entre os agentes, registro, processamento e relatórios das decisões bem como esclarecer quais são os critérios para verificação dos resultados parciais e final, foi incorporado ao módulo dos participantes.

\subsection{0 jogo TECON-AMBIENTAL}

As empresas do ambiente simulado no jogo do TECON-AMBIENTAL deverão prestar serviços aos seus clientes, os armadores, com eficiência e eficácia, buscando sempre atender a demanda do mercado e cumprir os prazos estabelecidos ao menor custo total e com a menor emissão de poluentes locais e globais, aumentando assim o índice de atratividade do seu terminal.

O módulo das equipes é de uso exclusivo dos gestores das empresas simuladas e é por meio deste que é possível gerenciar as operações de um terminal de contêineres e testar as decisões. Neste módulo, as equipes têm acesso a um ambiente determinístico e sem influência das decisões tomadas pelas equipes concorrentes. Além disto, este módulo gera, ao final de cada rodada, um arquivo que carrega as decisões que foram tomadas. Cada equipe irá encaminhar o seu arquivo com as decisões para o responsável pela aplicação do jogo, que irá processá-los no módulo do instrutor.

O módulo do instrutor é de uso exclusivo do responsável pela aplicação e é por meio deste que é possível realizar a interação entre as tomadas de decisão das equipes, considerando variáveis estocásticas e realizando comparações entre as tomadas de decisão de cada equipe. Após o responsável receber o arquivo com as decisões de todas as esquipes, são realizadas comparações por meio da normalização das variáveis. $\mathrm{O}$ processamento desses dados dá ori- 
gem ao indicador de atratividade de cada um dos terminais gerenciados pelas equipes, por meio do qual se distribui a demanda do jogo para as empresas. A empresa que acumular os melhores resultados ao longo do jogo é a que será a vencedora ao final da aplicação.

A gestão dos terminais portuários de contêineres do jogo TECON-AMBIENTAL, por meio do módulo dos participantes, possibilita a realização de simulações (etapas 1, $3,6,7,8,9$ e 10) antes das tomadas de decisão (etapas 2, 4, 5 e 11) que darão origem aos indicadores do terminal (etapas 12, 13 e 14) que subsidiarão a elaboração da proposta de gestão do terminal a ser comparada com as demais equipes (etapa 15). Assim, em cada rodada, é necessário que cada equipe realize as seguintes atividades: 1) Simular o histórico de demanda; 2) Definir um percentual da demanda a ser atendida; 3 ) Simular área de armazenagem necessária para atender a demanda a ser atendida; 4) Arrendar um terminal; 5) Configurar o terminal; 6) Simular a capacidade de atendimento do terminal 7) Investir em equipamentos, caso seja necessário; 8) Simular a produtividade do terminal; 9) Simular os custos do terminal; 10) Simular a emissão de poluentes; 11) Escolher um preço de movimentação para o contêiner; 12) Verificar o indicador operacional; 13) Verificar o indicador financeiro; 14) Verificar o indicador ambiental; 15) Gerar um arquivo que será enviado para o instrutor.

Na Figura 3 é apresentado um fluxograma que busca sintetizar as 15 etapas existentes no jogo TECON-AMBIENTAL. Já a Figura 4 ilustra uma das telas do jogo TECON -AMBIENTAL, que está associada às etapas $(6,7,8,9$ e 10).

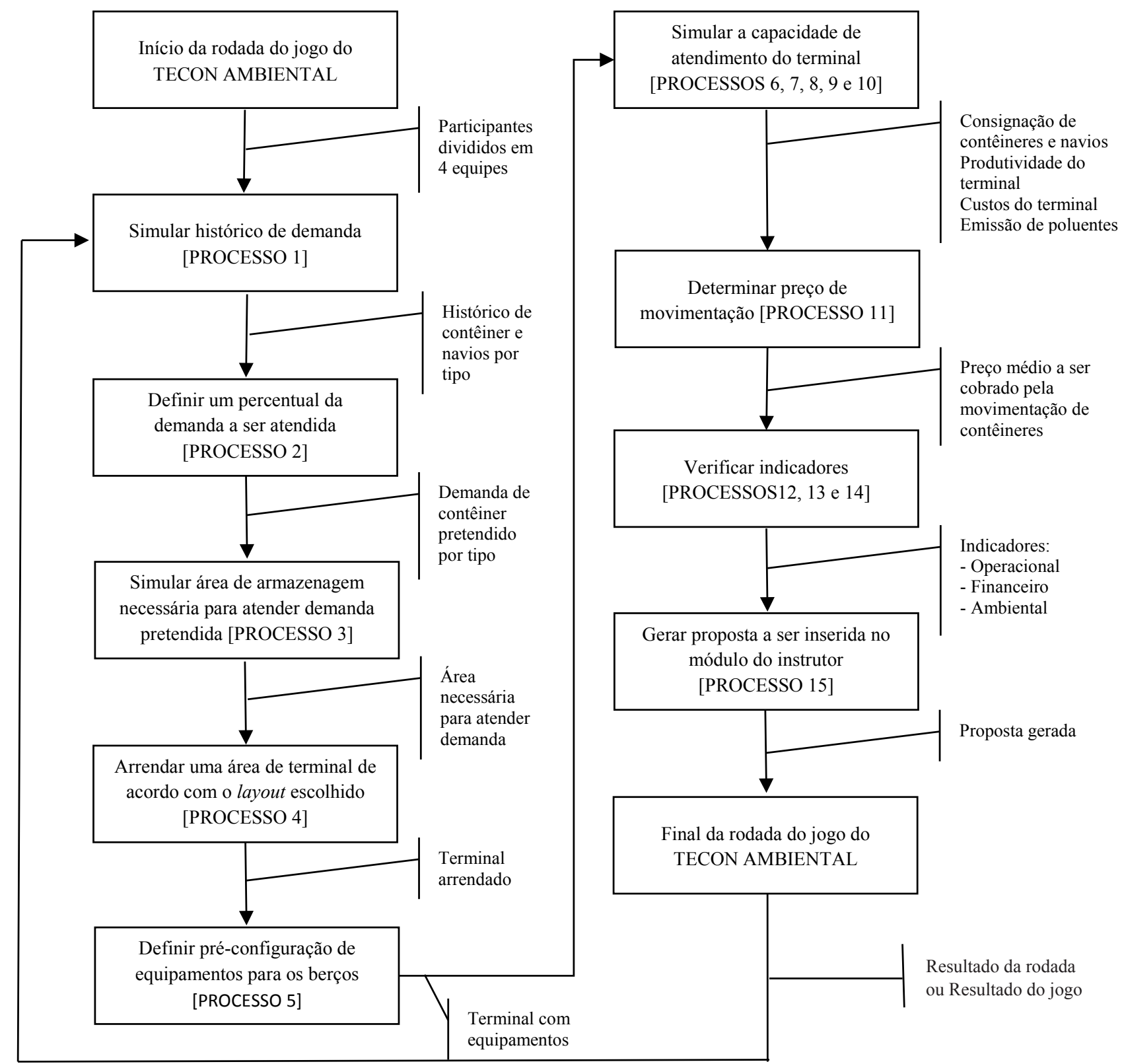

Figura 3: Processos realizados pelo participante da aplicação no Jogo TECON-AMBIENTAL Fonte: Elaboração própria (2014) 


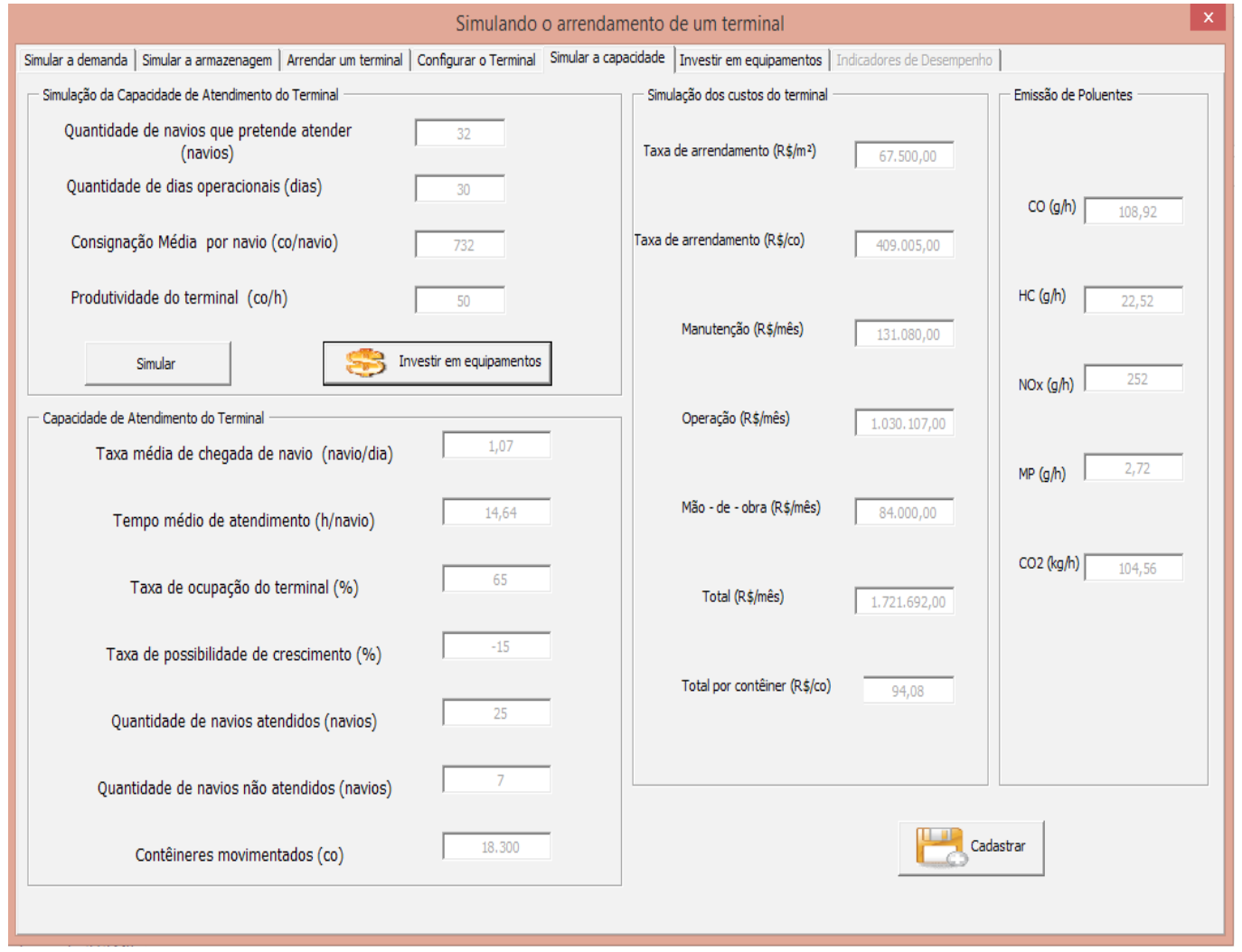

Figura 4: Telas do jogo TECON-AMBIENTAL: módulo das equipes

Fonte: Elaboração própria (2014)

Para gerar o resultado da rodada, o conteúdo das planilhas eletrônicas geradas pelas decisões dos gestores dos terminais é transferido para o módulo do instrutor. Para gerar um resultado (nota) para cada terminal, por rodada, o modelo utilizado no módulo do instrutor normaliza as informações recebidas e atribui um peso para cada um dos indicadores de forma que o somatório dos resultados alcançados forneça um valor entre 0 e 10 . Os resultados são acumulados a cada rodada e, ao final da aplicação do jogo TECON-AMBIENTAL, a empresa que tiver o maior conceito acumulado é a que foi melhor gerenciada e, consequentemente, é considerada a ganhadora.

\section{CONSIDERAÇÕES FINAIS}

A partir do objetivo deste trabalho, que foi o de relatar o desenvolvimento de um jogo de empresas, com aplicação em cursos de gestão portuária, capaz de simular as principais operações de um terminal de contêineres e seus principais impactos ambientais, conclui-se que as variáveis operacionais e ambientais utilizadas no modelo matemático para simular a gestão da operação de terminais de contêineres possuem verossimilhança com a realidade. Pode-se afirmar que a simulação realizada por meio do uso do jogo TECON-AMBIENTAL possui elementos suficientes para que haja transferência de conhecimento, desenvolvimento de habilidades e incentivo a atitudes, relacionados à gestão de terminais de contêineres, proporcionando que o participante vivencie a tomada de decisões durante a gestão das empresas simuladas e que possa aplicar o que aprendeu em outras situações.

As variáveis relacionadas ao planejamento operacional e tomada de decisão foram as mesmas utilizadas no Jogo do TECON: 1) Determinar área de armazenagem; 2)
Arrendar um layout de terminal de contêiner; 3) Investir em equipamentos portuários, 4) Analisar a capacidade de atendimento e 5) Determinar preço de movimentação de contêiner, acrescidas das variáveis ambientais relacionadas à área seca: operação dos principais equipamentos utilizados na movimentação dos contêineres: 1) Caminhão; 2) Reachstacker; 3) Transteiner e 4) Aranha.

Embora as variáveis ambientais contemplem apenas uma parte dos possíveis impactos da atividade portuária - relacionadas à operação (Não foram considerados os impactos relacionados à localização e à construção do empreendimento portuário) - estas são suficientes para que a discussão acerca do equilíbrio entre resultados operacionais e as decorrências ambientais dessas operações sejam consideradas no ambiente simulado, logo, servem como um preparo para a atividade real.

A utilização de um jogo de empresas - Jogo do TE$\mathrm{CON}$ (que não considera as variáveis ambientais em seu conjunto de decisões) - como base para o desenvolvimento do jogo TECON-AMBIENTAL, mostra-se como uma oportunidade: outros usuários e ou desenvolvedores de jogos podem incorporar variáveis de impactos ambientais em jogos que foram desenvolvidos em um momento em que a importância relativa dos impactos ambientais nas decisões econômico-financeiras não tinham a proporção atual. Novos jogos poderiam ser desenvolvidos com um esforço proporcionalmente menor quando comparado ao desenvolvimento de um novo jogo.

Quanto às dificuldades de inserir novas variáveis em um jogo de empresas existente, verificou-se que a ausência da documentação do software do jogo do TECON, no qual o jogo TECON-AMBENTAL foi baseado, levou a autora a ter que reaprender toda a lógica inicialmente 
utilizada para depois fazer as adaptações e ou inserções. O esforço e o tempo dedicados ao novo programa teriam sido menores se, no momento do desenvolvimento, a documentação referente à programação tivesse sido gerada e registrada.

Quanto às limitações desse trabalho, o jogo de empresas TECON-AMBIENTAL foi utilizado pela própria autora assumindo o papel de mediadora e gestora das equipes, ao mesmo tempo, para verificar se as relações entre as variáveis estavam adequadas: tomada de decisão e efeito gerado e, em um segundo momento, junto a um grupo de alunos (mestrandos e doutorandos) selecionados do Programa de Pós-graduação em Engenharia de Transporte da Universidade Federal do Rio de Janeiro (PET/COPPE/UFRJ), com o objetivo de verificar a consistência das relações. É necessário, ainda, aplicações e estudos direcionados à calibração do peso no resultado das equipes decorrentes das decisões relacionadas aos aspectos operacionais e ambientais. Ainda como oportunidade de novos estudos, está a aplicação do jogo de empresas TECON-AMBIENTAL junto a outros públicos (Tecnólogo, Graduação e Pós-graduação) ultrapassando sua proposta inicial direcionada para cursos Técnicos da área de portos.

\section{REFERÊNCIAS}

ANTAQ (2011). Meio Ambiente: gestão ambiental: introdução. Disponível em: < http://www.antaq.gov.br/portal/ MeioAmbiente_GA_Introducao.asp >. Acesso em: 15 fev. 2011.

ANATAQ (2013). Anuário estatístico 2013. Brasília, 8 de fevereiro de 2014. Disponível em: < http://www.antaq.gov.br/ Portal/Anuarios/Anuario2013/index.htm >. Acesso em: 22 maio 2014.

ANTAQ (2015a). Relatório estatístico semestral. Disponível em < http://www.antaq.gov.br/Portal/pdf/Relatorio_Estatistico_ Semestral_2015.pdf $>$. Acesso em: 7 dez. 2015.

ANTAQ (2015b). Meio ambiente: impactos ambientais. Disponível em $<$ http://www.antaq.gov.br/portal/ MeioAmbiente_ImpactosAmbientais.asp >. Acesso em: $15 \mathrm{dez}$. 2015.

Brasil (1981). Lei $n^{\circ} 6.938$, de 31 de agosto de 1981. Política Nacional do Meio Ambiente. Disponível em < http://www. planalto.gov.br/ccivil_03/Leis/L6938.htm >. Acesso em: 15 dez. 2015.

Carvalho, A. C. P. (2003). Uma Contribuição ao Estudo do Desempenho de Terminais de contêineres. Dissertação (Mestrado) - Programa de Engenharia de Transportes, Universidade Federal do Rio de Janeiro, COPPE, UFRJ.

Carvalho, A. C.; Abdallah, P. R. (2012). Análise da Gestão de Resíduos Sólidos no Terminal Porto Novo do Porto do Rio Grande, Brasil. Revista de Gestão Costeira Integrada, v. 12, n. 3, p. 389-398. Disponível em: < http://www.scielo.mec.pt/scielo. php?script $=$ sci_arttext\&pid $=$ S1646-88722012000300009\&lng=pt \&tlng $=$ pt $>$ Acesso em: 5 dez. 2015.
Coelho L. C. (2010). Logística portuária: os portos mais movimentados do Brasil e do mundo. Disponível em: $<$ http://www.logisticadescomplicada.com/logistica-portuaria-osportos-mais-movimentados-do-brasil-e-do-mundo/ > . Acesso em: 15 dez. 2015.

COPPE (2011). Inventário de Emissões Atmosféricas por Veículos Automotores do Estado do Rio de Janeiro. Programa de Engenharia de Transportes - PET/COPPE/UFRJ, Rio de Janeiro, RJ.

Cruz, M. M. C. (1997). Uma contribuição ao estudo da dinâmica de sistemas de terminais especializados de contêineres sobo enfoque sistêmico. Tese (Doutorado) - Programa de engenharia de transportes, COPPE, UFRJ.

D’Elboux, P. C. (2008). Jogos de empresa. Anuário da produção acadêmica docente, v. 12, n. 2. São Paulo: Faculdade Anhanguera de Santa Bárbara.

Fernandes, M. G. (2001). Modelo Econômico-operacional para análise de dimensionamento de terminais de contêineres e veículos. Dissertação (Mestrado) - Programa de Mestrado em Engenharia Naval e Oceânica. Escola Politécnica de São Paulo.

Frigo, A. L.; Bleninger, T. B. (2015). A review of the navigability modeling for inland waterways. E-proceedings of the 36 th IAHR World Congress. 28 June - 3 July, 2015, The Hague, the Netherlands. Disponível em: <http://89.31.100.18/ iahrpapers/86193.pdf>. Acesso em: 5 dez. 2015.

Gil, A. C. (2005). Metodologia do ensino superior. São Paulo: Atlas.

Goes Filho H. de. A (2008). Notas de aula da disciplina Planejamento portuário. Curso de pós-graduação.

Gomes, L. F. A. M., Araya, M. C. G. e Carignano, C. (2004). Tomada de decisões em cenários complexos: introdução aos métodos discretos do apoio multicritério à decisão - São Paulo: Pioneira Thomson Learning.

Gramigna, M.R. (2007). Jogos de empresa. $2^{\mathrm{a}}$ ed. Pearason Prentice Hall, São Paulo.

Gullo, L. M. G. (2007). O sistema de conteinerização. Inovação Uniemp, v. 3, n. 4, ago. 2007, Campinas. Disponível em: < http:// inovacao.scielo.br/scielo.php?script=sci_arttext\&pid=S1808$23942007000400012 \& \operatorname{lng}=$ pt\&nrm=iso $>$. acesso em: 26 nov. 2015.

ILOS - Instituto de Logística e Supply Chain (2014). Portos brasileiros: avaliação dos usuários e análise de desempenho: 2013. Disponível em: < http://www.ilos.com.br/ilos_2014/wpcontent/uploads/PANORAMAS/PANORAMA_brochura_portos. pdf $>$. Acesso em: 22 maio 2014.

Keys, J. B.; Biggs, W. D. (1990). A review of business games. In: Gentry, J. W. Guide to business gaming and experimental learning. London: Nichols G P Publishing, 1990. p. 48-73.

Lacruz, A. J. (2004). Jogos de empresa: considerações teóricas. Caderno de pesquisas em administração, São Paulo, v.11, n. 4, p. 93-109, out./dez. 
Leal Jr. I, C.; Lopes, J. M.; Guimarães, V. A; Teodoro, P. (2015). Technical and financial efficiency: analyzing brazilian container terminals. In: European Transporte Conference. Frankfurt, Germany. Sept. 2015. Disponível em: < http://trid.trb.org/view. aspx?id=1372698 >. Acesso em: $12 \mathrm{dez} .2015$.

Luperini, R (2008). Dinâmicas e jogos na empresa: Método, instrumento e práticas de treinamento. 2. ed. Rio de Janeiro: Vozes.

Motta G. S.; Mello, D. R. A.; Paixão, R. B. (2012). O jogo de empresas no processo de aprendizagem em administração: o discurso coletivo de alunos. RAC. Rio de Janeiro, v. 16, n. 3, p. 342-359, maio/jun.. Disponível em: < http://www.scielo.br/pdf/rac/ v16n3/v16n3a02 >. Acesso em: 22 maio 2014.

Oliveira, M. A., Sauaia, A. C. A. (2011). Impressão docente para aprendizagem vivencial: um estudo dos benefícios dos jogos de empresas. RAEP Administração: Ensino \& Pesquisa. Rio de Janeiro, v. 12 n. 3, p. 355-391, jul./set. 2011. Disponível em: < http://raep.emnuvens.com.br/raep/article/view/159 >. Acesso em: 11 dez. 2015.

Peixoto G. S. de. S e R. C, Botter (2005). Modelo para seleção de equipamentos de retaguarda e estratégias de formação de pilhas na armazenagem em terminais de contêineres. XIX Congresso Panamericano de Ingeniería Naval Transporte Marítimo e Ingeniería Portuária. Equador.

Sauaia, A. C. A. (1995). Jogos de Empresas: Aprendizagem com Satisfação. Revista de Administração, v. 32, n. 3, p. 13-27, jul/set 1995, São Paulo.

Silva, E. L. da; Menezes, E. M. (2001) Metodologia da pesquisa e elaboração de dissertação. $3^{\mathrm{a}}$ ed. UFSC/PPGEP/LED, Florianópolis, 2001.

Silva, S. D (2010) A utilização de jogos de empresa como ferramenta de ensino para formação profissional em terminais de contêineres. Dissertação de mestrado. Programa de Engenharia de Transportes - PET/COPPE/UFRJ. Universidade Federal do Rio de Janeiro. Rio de Janeiro, Brasil.

Silva, S. D (2010a). O Jogo do TECON-Uma Ferramenta de Apoio Educacional para Cursos Técnicos em Portos e Cursos Tecnológicos em Gestão Portuária. Anais do XXIV Congresso de Ensino e Pesquisa em Transportes - ANPET. Salvador - BA, Brasil.

Silva, S. D.; Souza, C. D. R.; D’Agosto, M. A. (2013). A utilização de metodologias participativas para aprimorar a formação profissional para o setor portuário: o caso do jogo do TECON. Transportes. São Carlos, v. 21, n. 1. DOI: 10.4237/ transportes.v21i1.578.

Tanabe, M. (1977). Jogos de empresas. Dissertação de mestrado. São Paulo: FEA/USP, 1977. 117 p.

Teodoro, P. (2015). Jogo de empresas: técnica de apoio ao processo de aprendizagem de adultos na área de logística: o caso do SOLOG (Simulador de Operações Logísticas). Tese (Doutorado) - Programa de Engenharia de Transportes - PET/COPPE/UFRJ. Universidade Federal do Rio de Janeiro. Rio de Janeiro, Brasil.
Teodoro, P.; D’Agosto, M. A.; Silva, Y. V. (2014). Jogo de empresas: simulador de operações logísticas - SOLOG: reação ao seu uso e percepção acerca de sua contribuição para o processo de ensino-aprendizagem de adultos na área de logística. Transportes. São Carlos, v. 22, n. 3. DOI: 10.14295/transportes. v22i3.803.

Valois, N. A. L. (2009). Proposição do uso de indicadores ambientais na avaliação de desempenho dos portos brasileiros. Dissertação de Mestrado. Universidade Federal de Pernambuco. Programa de pós-graduação em engenharia mecânica.

Yin, R. K. (2001). Estudo de Caso - Planejamento e Métodos - $2^{\mathrm{a}}$ ed. Porto Alegre: Bookman. 